\section{Foreign Body Granulomas after the Use of Dermal Fillers: Pathophysiology, Clinical Appearance, Histologic Features, and Treatment}

\author{
Jeong Min Lee, Yu Jin Kim \\ Department of Plastic and Reconstructive Surgery, Gachon University Gil Medical \\ Center, Incheon, Korea
}

Correspondence: Yu Jin Kim

Department of Plastic and Reconstructive Surgery, Gachon University Gil Medical Center,

21 Namdong-daero 774beon-gil, Namdong-gu, Incheon 405-760, Korea

Tel: +82-1577-2299, Fax: +82-32-460-2398, E-mail: pseugene@gilhospital.com

We are grateful to Prof. Kwan Hyun Youn for his high-quality medical illustrations.

No potential conflict of interest relevant to this article was reported.

Received: 7 Aug 2014 • Revised: 3 Sep 2014 • Accepted: 18 Sep 2014

pISSN: 2234-6163・ elSSN: 2234-6171

http://dx.doi.org/10.5999/aps.2015.42.2.232 • Arch Plast Surg 2015;42:232-239

Copyright (C) 2015 The Korean Society of Plastic and Reconstructive Surgeons

This is an Open Access article distributed under the terms of the Creative Commons Attribution

Non-Commercial License (http://creativecommons.org/licenses/by-nc/3.0/) which permits

unrestricted non-commercial use, distribution, and reproduction in any medium, provided the

original work is properly cited.

A foreign body granuloma is a non-allergic chronic inflammatory reaction that is mainly composed of multinucleated giant cells. Foreign body granulomas may occur after the administration of any dermal filler. Factors such as the volume of the injection, impurities present in the fillers, and the physical properties of fillers affect granuloma formation. The formation of granulomas involves five phases: protein adsorption, macrophage adhesion, macrophage fusion, and crosstalk. The clinical and pathologic features of granulomas vary depending on the type of filler that causes them. Foreign body granulomas can be treated effectively with intralesional corticosteroid injections. Surgical excisions of granulomas tend to be incomplete because granulomas have ill-defined borders and moreover, surgical excisions may leave scars and deformities.

Keywords Granuloma, foreign-body / Hyaluronic acid / Collagen / Silicone gels

\section{INTRODUCTION}

The foreign body reaction is the final stage of inflammation and wound healing process which occurs after implantation of various material such as a prosthesis, biomaterials or medical device, which is composed of macrophages and foreign body giant cells [1].

Foreign body granulomas can occur after the injection of dermal fillers, showing various clinical and histologic features depending on the type of injected filler. The reported incidence of foreign body granulomas after filler injection varies. Hyaluronic acid and collagen are the most commonly used filler materials. The incidence of foreign body granulomas after the injection of hyaluronic acid has been reported as $0.02 \%-0.4 \%$, and the incidence of foreign body granulomas after the injection of bovine collagen has been reported as $0.04 \%-0.3 \%$ [2-4].

Both nodules and foreign body granulomas are terms that have been used for palpable lesions noted after filler injections. These terms were once used interchangeably, but they are now used with distinct meanings. In general, foreign body granulomas are not allergic reactions and are often triggered by a systemic bacterial infection, which means that it is not yet possible to predict which patients are at risk [4]. The aim of this article is to present a review of the literature regarding the definition, pathophysiology, clinical features, histology, and treatment of foreign body granulomas according to the type of filler used.

\section{DEFINITION}

A granuloma is a chronic inflammatory reaction with various etiologies and can be defined as a tumor composed of a collection of immune cells, mainly macrophages [5]. Macrophages are the main cells that constitute granulomas, and in the case of foreign body granulomas, macrophages are activated and fused into multinucleated giant cells $[6,7]$. These giant cells are characterized by a haphazard arrangement of more than 20 nuclei [5]. The activated macrophages are sometimes called epithelioid cells because their shape is similar to epithelial cells.

Filler-related foreign body granulomas are non-allergic reactions that occur 6-24 months after filler injections and are granulomas mainly composed of multinucleated giant cells $[4,5,8]$.

Duranti et al. [9] classified the severity of foreign body granuloma into four grades in terms of the types and number of cells present (Table 1).

\section{PATHOPHYSIOLOGY}

Foreign body granulomas are caused by granulomatous inflammation after the aggregation of macrophages in response to large foreign bodies that cannot be phagocytosed by macrophages [10]. Studies have demonstrated that this process consists of several phases: protein adsorption, macrophage adhesion, macrophage fusion, and crosstalk $[1,7,11,12]$. In this review, we divided the process into five phases (Fig. 1).

\section{Recognition and inflammation}

The foreign body response begins with rapid neutrophil infiltration and the instantaneous adsorption of various host proteins to foreign material. In the host reaction following the implantation of foreign material, circulating polymorphonuclear leukocytes, mainly neutrophils, move into the soft tissue as the first 
line of defense. Attacking leukocytes release opsonins and soluble factors. If the neutrophils are unable to successfully phagocytose the particle, macrophages take on a more dominant role in the process [10].

\section{Adsorption of plasma proteins}

Biomaterials and other foreign material immediately acquire a layer of host proteins prior to interacting with host cells. The presence of adsorbed proteins such as complement, fibronectin, vitronectin, and others modulate the host inflammation and wound healing response [1]. Physical properties such as particle size, surface shape, surface charge, and particle concentration can influence phagocytosis.

\section{Macrophage adhesion}

The progression of events in inflammation requires the extravasation and migration of monocytes to the implant site. The guided movement of monocytes occurs in response to chemokines and other chemoattractants. Monocytes circulating in the blood slowly migrate to the surrounding tissues and differentiate into macrophages. Macrophages typically have a life span of several months and replace themselves at a rate of less than $1 \%$ per day [12]. When they die, phagocytosed foreign bodies are released, which can cause a recurrence of active, destructive inflammation months or years later [7].

\section{Table 1. Four grades of foreign body granulomas}

\begin{tabular}{|ll|}
\hline Grade & \multicolumn{1}{c|}{ Clinical or histologic features } \\
\hline 0 & No visible reaction \\
1 & Slight reaction with a few inflammatory cells \\
2 & Clear inflammatory reaction with one or two giant cells \\
3 & Fibrous tissue with inflammatory cells, lymphocytes and giant cells \\
4 & Granuloma with encapsulated implant-clear foreign body reaction \\
\hline
\end{tabular}

\section{Macrophage fusion (foreign body giant cell formation)}

Circulating monocytes are $12-15 \mu \mathrm{m}$ in diameter; macrophages are $25-30 \mu \mathrm{m}$. Macrophages can ingest up to $25 \%$ of their volume per hour [12]. Particle size is important in phagocytosis, but size is not the sole determinant of effective phagocytosis. In the case where the particle volume is greater than the volume of a macrophage, macrophage aggregation is required and foreign body giant cells are formed. When multiple macrophages meet each other to fuse, all cells need a stimulus such as interleukin-4 or interleukin-13 [1].

\section{Crosstalk between foreign body giant cell and others}

Macrophages and foreign body giant cells secrete an array of inflammatory mediators. They are capable of secreting growth and angiogenic factors that are important in the regulation of fibroproliferation. Macrophages secrete factors that recruit and activate fibroblasts, and a fibrous capsule develops around the foreign material. Lymphocytes play a critical role in the foreign body reaction. Both direct (juxtacrine) and indirect (paracrine) mechanisms of interaction between lymphocytes and macrophages occur at the tissue/material interface [1].

However, this sequence of events does not accurately describe the formulation of foreign body granulomas caused by smallparticle fillers or silicone fluid, because small-particle and fluid fillers are easily phagocytosed by macrophages $[13,14]$. Foreign body granulomas sometimes simultaneously occur in multiple sites if filler was injected at multiple sites; however, additional theories have attempted to explain their occurrence [4]. It is well known that macrophages act as memory cells, which underlies a distinct proposed mechanism for macrophage action [5]. Lemperle et al. $[4,15]$ proposed a hypothesis that macrophages remember small, phagocytosed chemical structures and stimulations such as severe systemic infection can trigger giant cell formation and foreign body granuloma formation [15-17].

\section{Fig. 1. Five phases of the formation of foreign body granulomas}

The foreign body response begins rapid neutrophil infiltration, which is with the instantaneous adsorption of various host proteins to the foreign material. The foreign material immediately acquires a layer of host proteins prior to interacting with host cells. Circulating monocytes in the blood slowly migrate to the surrounding tissues and differentiate into macrophages. In cases where the particle volume is greater than the macrophage volume, macrophage aggregation is required and foreign body giant cells are formed. Macrophages secrete factors that recruit and activate fibroblasts, and a fibrous capsule develops around the material. FBGC, foreign body giant cell.

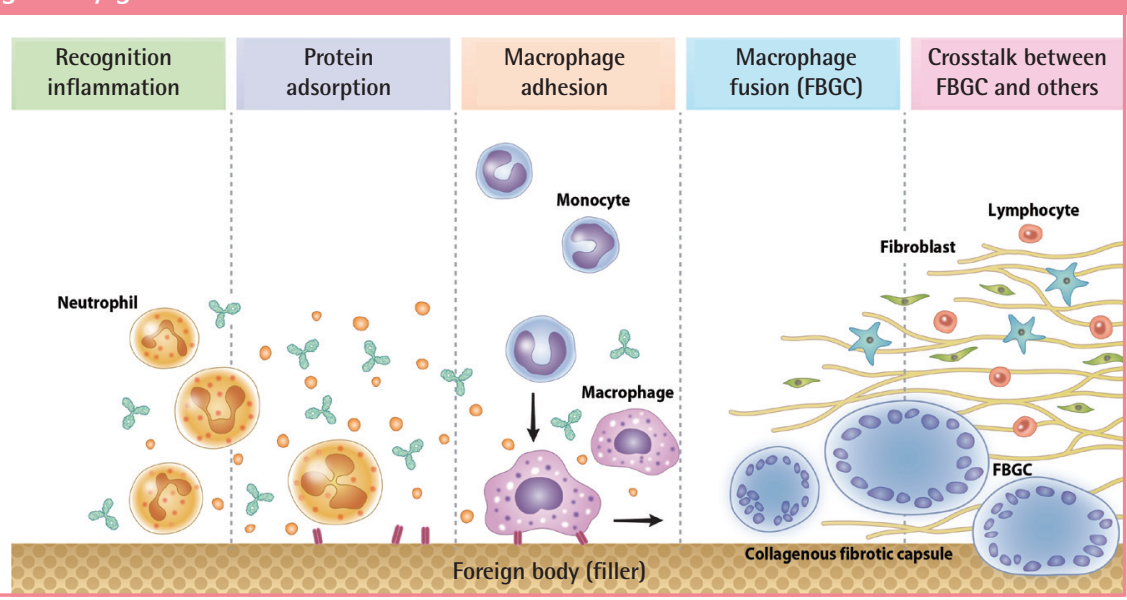




\section{FACTORS AFFECTING THE OCCURRENCE OF FOREIGN BODY GRANULOMAS}

Bentkover [10] described the factors that affect phagocytosis based on the hypothesis that granulomas are formed when there are filler particles that cannot be phagocytosed by macrophages. Lemperle et al. [4] also described the factors that affect the formation of foreign body granulomas. Among these factors, the particle surface and the presence of impurities stood out as particularly relevant: when improved products were used, a lower occurrence rate of foreign body granulomas was noted (Table 2) $[4,10,12,13,18-21]$.

\section{CLINICAL FEATURES OF FOREIGN BODY GRANULOMAS}

Lemperle et al. $[4,8]$ divided foreign body granulomas into three types based on clinical features: cystic granulomas, edematous granulomas, and sclerosing granulomas. The type of foreign body granulomas primarily depends on the type of filler used, but this is not always the case. Moreover, mixed type foreign body granulomas sometimes occur.

\section{FEATURES OF FOREIGN BODY GRANULOMAS ACCORDING TO FILLERMATERIALS}

The histologic features of foreign body granulomas vary depending on the filler used (Table 3).

\section{Hyaluronic acid}

Hyaluronic acids normally present in the human body have a half-life of 1-2 days. However, hyaluronic acids used as fillers are modified to add artificial cross-linking, which allows them to

Table 2. Factors that influence granulomas caused by dermal fillers

\begin{tabular}{|ll|}
\hline Factor & References \\
\hline Injected volume & Lemperle et al. [4] \\
& Jones et al. [18] \\
& Duffy et al. [19] \\
Repeated injections & Lemperle et al. [4] \\
Impurities & Jones et al. [18] \\
& Lemperle et al. [13] \\
Particle size & Champion and Mitragotri [20] \\
Particle surface smoothness & Lemperle et al. [21] \\
& Champion and Mitragotri [20] \\
Particle surface charge & Bentkover [10] \\
Hydrophilicity & Freitas [12] \\
\hline
\end{tabular}

maintain their volume for more than six months in the human body. Clinically, foreign body granulomas caused by hyaluronic acids mainly appear as cystic granulomas. A process of encapsulation occurs that prevents the absorption of injected material into the surrounding tissues, resulting in the development of a sterile abscess. Histologically, palisaded granulomatous tissue mainly composed of giant cells and macrophages is usually discovered [2].

\section{Collagen}

As with hyaluronic acids, foreign body granulomas caused by collagen fillers mainly show the characteristics of cystic granulomas. The reported incidence rate was $0.1 \%-1.3 \%$ in one study [3] and 4.5\% in another [22]. They generally show clinical features similar to abscesses and contain many giant cells and macrophages $[3,4]$.

\section{Silicone fluid}

Injectable medical-grade silicone fluid was developed and introduced in the late 1950s and advanced silicone gel fillers are now available for off-label use. However, in the past, non-medicalgrade silicone fluid was also used for augmentation in many patients. Both medical-grade and non-medical grade silicone fluid can induce foreign body granulomas. Foreign body granulomas may even occur 10 to 15 years after the injection of silicone fluids with a high rate of incidence. Relatively soft and fixed nodules are palpable and swelling-like symptoms occur, accompanied by redness. Lipogranulomas caused by silicone fluids usually show vacuoles of various sizes with diameters of 1-30 $\mu \mathrm{m}$, surrounded by lymphocytes, plasma cells, eosinophils, and scattered giant cells (Fig. 2) [14,23]. Similar findings have been observed in silicone gel bleedings among patients who received breast augmentation with cohesive gels.

\section{Paraffin}

In the past, paraffin injection was often performed in augmentations of the nose, forehead, and breasts [24]. However, sclerosing granulomas have occurred up to 20 years after paraffin

Table 3. Characteristic features of foreign body granulomas according to filler materials

\begin{tabular}{ll|}
\hline Histologic feature & \multicolumn{1}{c}{ Filler } \\
\hline Cystic granuloma & Hyaluronic acid \\
& Collagen \\
Lipogranuloma & Silicone fluid \\
(Swiss cheese pattern) & $\begin{array}{l}\text { Paraffin } \\
\text { Polyacrylamide gel }\end{array}$ \\
Sclerosing granuloma & $\begin{array}{l}\text { Polymethylmethacrylate microspheres } \\
\text { Polylactic acid microspheres }\end{array}$ \\
\hline
\end{tabular}




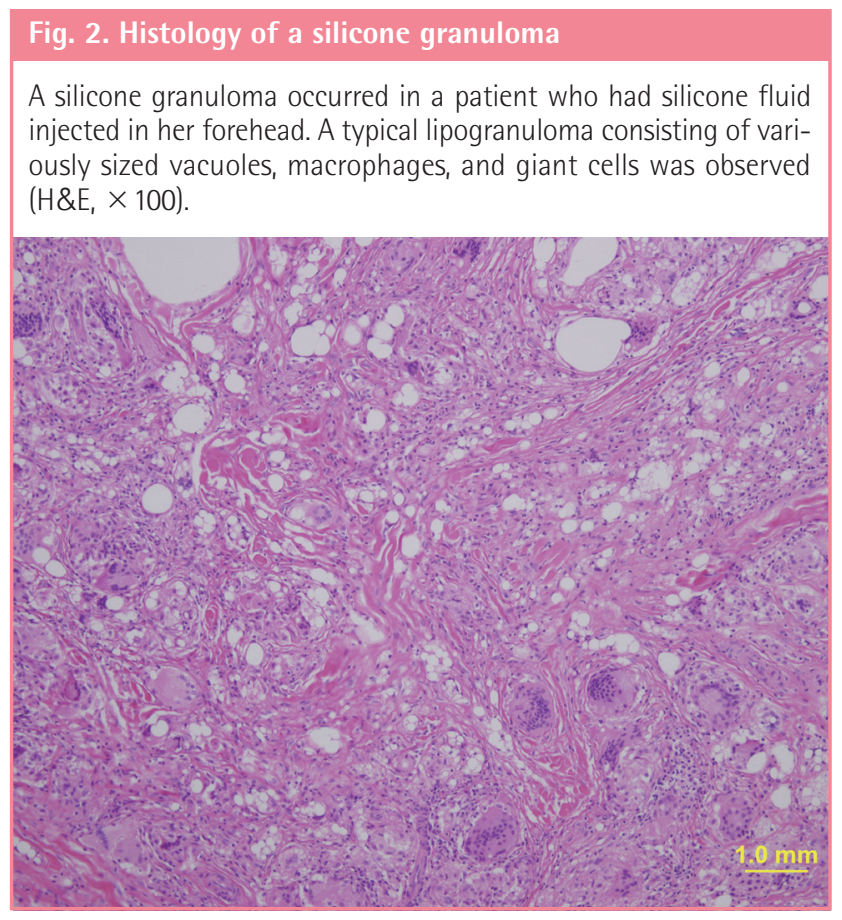

injections, and many patients currently suffer from paraffinrelated granulomas [25]. Paraffinomas generally result from the injection of oily substances containing long-chain acyclic hydrocarbons such as mineral oil [3]. It usually manifests as irregular plaque-like indurations of the skin. Macroscopically, excised specimens are white or grayish-white; microscopically, the granulomatous inflammation appears to have multiple, clear vacuoles, resulting in the so-called "Swiss cheese" pattern [26]. The clinical and histological features of paraffin granulomas are similar to those of granulomas due to silicone fluids (Fig. 3).

\section{Polyacrylamide gels}

Symptoms like pain, redness, and swelling after injections with Aquamid (Contura International S.A., Copenhagen, Denmark) should be considered as suspected infections and should never be treated with corticosteroids or non-steroidal anti-inflammatory drugs, but instead should be treated with high-dose, broadspectrum antibiotics. Polyacrylamide gels have been commonly injected in large quantities for breast and buttock augmentation in China and Russia. The clinical appearance and histologic findings associated with polyacrylamide gel granulomas are similar to those of granulomas caused by silicone fluids. Because Aquamid is highly biocompatible and does not cause cellular ingrowth or capsule formation, the migration of the polyacrylamide gel sometimes occurs in patients who have loose connective tissue $[4,27]$. However, it can be removed up to 10 years after the initial injection by needle aspiration or puncturing and squeezing [28].

\section{Fig. 3. Histology of a paraffin granuloma}

A foreign body granuloma occurred in a patient several years after paraffin injection for nasal augmentation. A Swiss cheese-patterned lipogranuloma consisting of giant cells, macrophages, and vacuoles of various sizes was observed $\left(H \& E_{1} \times 100\right)$.

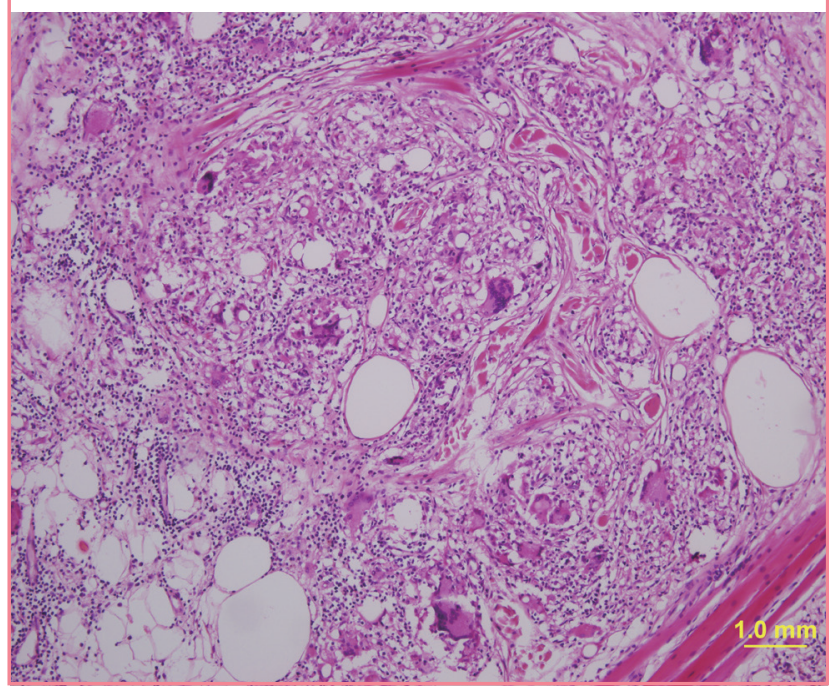

\section{Polymethylmethacrylate microspheres}

Artecoll (Rofil Medical B.V., Breda, Netherlands) is a mixture of bovine collagen and polymethylmethacrylate (PMMA) microspheres that have a smooth surface and diameter ranging between 30-42 $\mu \mathrm{m}$. Until recently, Artecoll was commonly used. When foreign body granulomas occur in patients who have been treated with Artecoll, they generally show the features of sclerosing granulomas. Several months after the filler injection, they appear as hard and bluish nodules with congested dermal capillaries on their surfaces. Pathologically, abnormally distributed microspheres are found as empty vacuoles with even sizes and shapes. The spaces between the vacuoles are filled with multinucleated giant cells, macrophages, fibroblasts, and collagen fibers produced by fibroblasts [23].

\section{Polylactic acid microspheres}

New-Fill/Sculptra (Dermik Laboratories, Berwyn, PA, USA), a polymer of polylactic acid (PLA), is usually diluted with sterile water several hours before injection. Micro- or macro-nodular cystic reactions and inflammatory nodules have been observed. The incidence of nodules is more frequent with intradermal implantation, with high concentrations of PLA, when it is used in highly mobile areas like in periorbital and dorsal skin [29]. However, PLA microspheres used as fillers sometimes cause foreign body granulomas similar to those caused by suture materials made of PLA. PLA-related granulomas appear 6-24 months after injection and last for 2-5 years if not treated. PLA mainly produces sclerosing granulomas like other particulate fillers; 
therefore, the histologic findings associated with PLA-related granulomas are similar to those associated with other particulate fillers. They may disappear with corticosteroid injections. Using polarized light microscopy, quite characteristic birefringence of the cystic spaces can be observed [4].

\section{Calcium hydroxyapatite microspheres}

Calcium hydroxyapatite is the main component of bone and teeth and is highly biocompatible; therefore; it causes little tissue ingrowth and does not cause granuloma formation. Lumps in the skin, especially in the lip, after calcium hydroxyapatite injection are usually nodules rather than foreign body granulomas; therefore, are not susceptible to steroid injection therapy [30].

\section{DIFFERENTIAL DIAGNOSIS}

\section{Nodules}

A nodule is a single lump that occurs at the injection site a few weeks after the filler injection. Most nodules are caused by technical errors and usually occur around the mouth and eyes when dermal fillers are injected superficially. Foreign body granulomas are different from nodules in that the size of the granuloma becomes larger than the volume that was injected, and granulomas develop simultaneously at multiple sites of injection [4]. Nodules are evenly sized and whiter in coloration than granulomas. They are harder than foreign body granulomas and show little cellular reaction; thus, intralesional steroid injections are a relatively difficult and ineffective treatment. However, nodules can be treated successfully by excision.

\section{Delayed hypersensitivity}

Delayed hypersensitivity reactions usually occur one month after filler injections and differ from foreign body granulomas regarding the time of onset and treatment strategies [3,31]. These reactions usually resolve spontaneously within one year without any sequelae, but oral steroids may be helpful [32]. Dermal fillers containing hyaluronic acid or collagen may induce delayed hypersensitivity reactions $[33,34]$. To lower the incidence rate of delayed hypersensitivity reactions, a single or double skin test is recommended before the injection of collagen fillers $[35,36]$. A positive skin test, erythema, edema, an indurated papule, a nodule, and/or itching are characteristic clinical features of delayed hypersensitivity [35].

\section{TREATMENT}

\section{Intralesional injections}

The primary treatment of foreign body granulomas caused by fillers is intralesional corticosteroid injections. The local injection of corticosteroids is known to interfere with the activities of fibroblasts, macrophages, giant cells, and with collagen synthesis $[37,38]$. When performing intralesional steroid injections, it is preferable to inject a high dose of triamcinolone mixed with lidocaine to prevent recurrence. Many reports have successfully treated foreign body granulomas caused by Artecoll [39,40], hyaluronic acids $[41,42]$ and Matridex (Biopolymer $\mathrm{GmbH}$, Montabaur, Germany) [43] using intralesional steroid injections. Bleomycin has been injected into keloids or hypertrophic scars, and it may work successfully in the treatment of foreign body granulomas $[44,45]$. In addition, 5-Fluorouracil, an antimitotic agent, has been used in intralesional injections to treat foreign body granulomas [38].

We recommend a $0.5 \mathrm{~mL}$ or $1 \mathrm{~mL}$ insulin syringe with a 30 -gauge needle for intralesional injections. A smaller diameter syringe allows the resistance of the granuloma to be sensed, which helps prevent corticosteroid-induced dermal atrophy. The preferred technique is to inject a small amount of drugs gradually, moving from the periphery to the central area, as granulomas tend to spread into the surrounding tissue in a finger-like pattern.

\section{Systemic therapy}

Systemic steroid therapy can be used for recurring foreign body granulomas. When systemic therapy is used, the doses of steroids should be higher than those used in local injections are. The use of oral prednisone at a starting dose and maintenance dose of $30 \mathrm{mg} /$ day and $60 \mathrm{mg} /$ day, respectively, is recommended to prevent the recurrence of granulomas [4].

Minocycline combined with oral or intralesional steroids is effective in treating widespread inflammatory granulomas [46]. It has also been reported that silicone granulomas have successfully been treated with minocycline only [46-48]. In addition, the systemic treatment of foreign body granulomas using allopurinol $[49,50]$, colchicines [51], and cyclosporine [52] has been reported.

\section{Surgical therapy}

The excision of foreign body granulomas is not a therapy of first choice because the complete removal of a granuloma is impossible in many cases. Genuine granulomas are invasive and have non-confined borders with the surrounding tissue [8]. There are also possibilities of complications such as abscess or fistula formation after surgery in granulomas that become induced by silicone fluid or acrylamide gel [53]. In the case of an obvious sterile abscess, incision and drainage of the abscess is an effective treatment [8]. The excision of a localized sclerosing granuloma can be carefully attempted and subsequent deformities can be 


\section{Table 4. Treatment of foreign body granulomas}

\begin{tabular}{|ll}
\hline Intralesional injections & Corticosteroids \\
& Bleomycin \\
& 5-Fluorouracil \\
Systemic therapy & Prednisolone \\
& Minocyline \\
& Allopurinol \\
& Colchinicine \\
& Cyclosporine \\
Surgical therapy & Excision \\
& Incision and drainage \\
& Fat graft or flaps
\end{tabular}

corrected using fat grafts or flaps (Table 4).

\section{CONCLUSIONS}

In the treatment of foreign body granulomas, it is necessary to consider intralesional steroid injection as a primary treatment option, because most foreign body granulomas can be treated successfully using intralesional steroid injection. Furthermore, a differential diagnosis should be performed to distinguish granulomas from nodules, and appropriate treatment in accordance with the type and cause of granuloma is required.

To prevent granulomas, injecting fillers into the subcutaneous fat layer are considered safer than injecting them into the dermal layer [54]. This is because the skin has very strong immune function and actively performs foreign body reactions [4].

\section{REFERENCES}

1. Anderson JM, Rodriguez A, Chang DT. Foreign body reaction to biomaterials. Semin Immunol 2008;20:86-100.

2. Micheels P. Human anti-hyaluronic acid antibodies: is it possible? Dermatol Surg 2001;27:185-91.

3. Ko CJ, Glusac EJ, Shapiro PE. Noninfectious granulomas. In: Lever WF, Elder DE, editors. Lever's histopathology of the skin. Philadelphia: Wolters Kluwer Health/Lippincott Williams \& Wilkins; 2009. p.373-87.

4. Lemperle G, Gauthier-Hazan N, Wolters M, et al. Foreign body granulomas after all injectable dermal fillers: part 1 . Possible causes. Plast Reconstr Surg 2009;123:1842-63.

5. Williams GT, Williams WJ. Granulomatous inflammation: a review. J Clin Pathol 1983;36:723-33.

6. Murphy KM, Travers P, Walport M. Janeway's immunobiology. New York: Garland Science; 2008.

7. Rubin E, Farber JL. Pathology. Philadelphia: Lippincott-Raven; 1999.

8. Lemperle G, Gauthier-Hazan N. Foreign body granulomas after all injectable dermal fillers: part 2. Treatment options.
Plast Reconstr Surg 2009;123:1864-73.

9. Duranti F, Salti G, Bovani B, et al. Injectable hyaluronic acid gel for soft tissue augmentation. A clinical and histological study. Dermatol Surg 1998;24:1317-25.

10. Bentkover SH. The biology of facial fillers. Facial Plast Surg 2009;25:73-85.

11. Grainger DW. All charged up about implanted biomaterials. Nat Biotechnol 2013;31:507-9.

12. Freitas RA. Nanomedicine. Austin, TX: Landes Bioscience; 2003.

13. Lemperle G, Romano JJ, Busso M. Soft tissue augmentation with artecoll: 10-year history, indications, techniques, and complications. Dermatol Surg 2003;29:573-87.

14. Zimmermann US, Clerici TJ. The histological aspects of fillers complications. Semin Cutan Med Surg 2004;23:241-50.

15. Lemperle G, Rullan PP, Gauthier-Hazan N. Avoiding and treating dermal filler complications. Plast Reconstr Surg 2006; 118:92S-107S.

16. Orentreich DS. Liquid injectable silicone: techniques for soft tissue augmentation. Clin Plast Surg 2000;27:595-612.

17. Achauer BM. A serious complication following medicalgrade silicone injection of the face. Plast Reconstr Surg 1983; 71:251-4.

18. Jones DH, Carruthers A, Orentreich D, et al. Highly purified 1000-cSt silicone oil for treatment of human immunodeficiency virus-associated facial lipoatrophy: an open pilot trial. Dermatol Surg 2004;30:1279-86.

19. Duffy DM. Tissue injectable liquid silicone: new perspectives. In: Klein AW, editor. Tissue augmentation in clinical practice: procedures and techniques. 2nd ed. New York: Taylor \& Francis; 2005. p. 159-162.

20. Champion J, Mitragotri S. Recognition of the size of polymer drug carriers by macrophages [Internet]. San Francisco, CA: American Institute of Chemicla Enginerrs Anuunal Meeting; 2006 [cited 2009 Mar 30]. Available from: https://aiche. confex.com/aiche/2006/techprogram/P66762.HTM.

21. Lemperle G, Hazan-Gauthier N, Lemperle M. PMMA microspheres (Artecoll) for skin and soft-tissue augmentation. Part II: Clinical investigations. Plast Reconstr Surg 1995;96: 627-34.

22. Cooperman LS, Mackinnon V, Bechler G, et al. Injectable collagen: a six-year clinical investigation. Aesthetic Plast Surg 1985;9:145-51.

23. Requena C, Izquierdo MJ, Navarro $M$, et al. Adverse reactions to injectable aesthetic microimplants. Am J Dermatopathol 2001;23:197-202.

24. Wong KT, Lee PS, Chan YL, et al. Paraffinoma in anterior abdominal wall mimicking liposarcoma. Br J Radiol 2003; 
76:264-7.

25. Legaspi-Vicerra ME, Field LM. Paraffin granulomata, "Witch's Chin," and nasal deformities: excision and reconstruction with reduction chinplasty and open rhinotomy resection. J Clin Aesthet Dermatol 2010;3:54-8.

26. Uchida Y, Yoshii N, Kubo H, et al. Facial paraffinoma after cosmetic paraffin injection. J Dermatol 2007;34:798-800.

27. Evstatiev D. Late complications after injections of hydrogel in the breast. Plast Reconstr Surg 2004;113:1878.

28. Tvede M, Christense L. Treatment guidelines [Internet]. Soeborg: AQUAMID; 2013 [cited 2014 Oct 13]. Available from: http://www.aquamid.com/wp-content/uploads/ 2014/03/Treatment_Guidelines_EN.pdf.

29. Andre P, Lowe NJ, Parc A, et al. Adverse reactions to dermal fillers: a review of European experiences. J Cosmet Laser Ther 2005;7:171-6.

30. Lemperle G, Morhenn V, Charrier U. Human histology and persistence of various injectable filler substances for soft tissue augmentation. Aesthetic Plast Surg 2003;27:354-66.

31. Heise H, Zimmermann R, Heise P. Temporary granulomatous inflammation following collagen implantation. J Craniomaxillofac Surg 2001;29:238-41.

32. Ozturk CN, Li Y, Tung R, et al. Complications following injection of soft-tissue fillers. Aesthet Surg J 2013;33:862-77.

33. Delustro F, Mackinnon V, Swanson NA. Immunology of injectable collagen in human subjects. J Dermatol Surg Oncol 1988; 14:49-55.

34. Geisler D, Shumer S, Elson ML. Delayed hypersensitivity reaction to Restylane. Cosmet Dermatol 2007;20:784-6.

35. Lowe NJ, Maxwell CA, Patnaik R. Adverse reactions to dermal fillers: review. Dermatol Surg 2005;31:1616-25.

36. Swanson NA, Stoner JG, Siegle RJ, et al. Treatment site reactions to Zyderm Collagen Implantation. J Dermatol Surg Oncol 1983;9:377-80.

37. Tujebajeva RM, Graifer DM, Matasova NB, et al. Selective inhibition of the polypeptide chain elongation in eukaryotic cells. Biochim Biophys Acta 1992;1129:177-82.

38. Conejo-Mir JS, Sanz Guirado S, Angel Munoz M. Adverse granulomatous reaction to Artecoll treated by intralesional 5-fluorouracil and triamcinolone injections. Dermatol Surg 2006;32:1079-81.

39. Al-Qattan MM. Late artecoll granulomas aggravated by pregnancy. Ann Plast Surg 2007;58:592.

40. Park TH, Seo SW, Kim JK, et al. Clinical experience with polymethylmethacrylate microsphere filler complications. Aesthetic Plast Surg 2012;36:421-6.
41. Lupton JR, Alster TS. Cutaneous hypersensitivity reaction to injectable hyaluronic acid gel. Dermatol Surg 2000;26: 135-7.

42. Senet P, Bachelez H, Ollivaud L, et al. Minocycline for the treatment of cutaneous silicone granulomas. $\mathrm{Br} J$ Dermatol 1999; 140:985-7.

43. Yang JH, Lee SM, Won $\mathrm{CH}$, et al. Foreign body granuloma caused by hyaluronic acid/dextranomer microsphere filler injection. Int J Dermatol 2012;51:1517-8.

44. Espana A, Solano T, Quintanilla E. Bleomycin in the treatment of keloids and hypertrophic scars by multiple needle punctures. Dermatol Surg 2001;27:23-7.

45. Saray Y, Gulec AT. Treatment of keloids and hypertrophic scars with dermojet injections of bleomycin: a preliminary study. Int J Dermatol 2005;44:777-84.

46. Lemperle G, Duffy DM. Treatment options for dermal filler complications. Aesthet Surg J 2006;26:356-64.

47. Arin MJ, Bate J, Krieg T, et al. Silicone granuloma of the face treated with minocycline. J Am Acad Dermatol 2005;52:536.

48. Garcia VS, Trelles AS. Superficial granulomatous pyoderma: successful treatment with minocycline. J Eur Acad Dermatol Venereol 2006;20:1134-5.

49. Reisberger EM, Landthaler M, Wiest L, et al. Foreign body granulomas caused by polymethylmethacrylate microspheres: successful treatment with allopurinol. Arch Dermatol 2003; 139:17-20.

50. de Barros Silveira LK, de Oliveira FL, Alves Tde B, et al. The therapeutic benefit of allopurinol in the treatment of foreign body granulomas caused by polymethylmethacrylate microspheres. Case Rep Dermatol Med 2012;2012:945205.

51. Aivaliotis M, Kontochristopoulos G, Hatziolou E, et al. Successful colchicine administration in facial granulomas caused by cosmetic implants: report of a case. J Dermatolog Treat 2007;18:112-4.

52. Baumann LS, Kerdel F. The treatment of bovine collagen allergy with cyclosporin. Dermatol Surg 1999;25:247-9.

53. Alijotas-Reig J, Garcia-Gimenez V. Delayed immune-mediated adverse effects related to hyaluronic acid and acrylic hydrogel dermal fillers: clinical findings, long-term follow-up and review of the literature. J Eur Acad Dermatol Venereol 2008;22:150-61.

54. Lee SC, Kim JB, Chin BR, et al. Inflammatory granuloma caused by injectable soft tissue filler (Artecoll). J Korean Assoc Oral Maxillofac Surg 2013;39:193-6. 


\section{- Quiz}

In pathology, a granuloma is an organized collection of . Circulating monocytes migrate to the foreign material implantation site and differentiate into .Which is the correct word to fill both blanks?

1. Neutrophils

2. Lymphocytes

3. Macrophages

4. Fibroblasts

5. Keratinocytes

Which is the first-line treatment of foreign body granulomas after filler injection?

1. Surgical excision

2. Systemic steroid therapy

3. IV Antibiotic therapy

4. Intralesional injection of corticosteroids

5. Intralesional injection of hyaluronidase

Which of the following is the injectable filler material that requires a skin test before injection?

1. Hyaluronic acid

2. Calcium hydroxylapatite

3. Polylactic acid

4. Collagen

5. Silicone

Which of the following is the injectable filler material that resembles lipogranulomas in pathologic evaluation?

1. Hyaluronic acid

2. Calcium hydroxylapatite

3. Polylactic acid

4. Collagen

5. Silicone 